S1 Table. Detailed information of $\boldsymbol{R}$. ecuadoriensis samples used in this study.

\begin{tabular}{|c|c|c|c|c|c|c|c|c|c|c|c|}
\hline $\begin{array}{c}\text { Sample site } \\
\text { and sample ID }\end{array}$ & $\begin{array}{c}\text { DNA } \\
\text { concentration } \\
n g / \mu L\end{array}$ & $\begin{array}{c}260 / 280 \\
\text { ratio }\end{array}$ & $\begin{array}{c}260 / 230 \\
\text { ratio }\end{array}$ & Latitude & Longitude & $\begin{array}{l}\text { House } \\
\text { ID }\end{array}$ & Habitat & $\begin{array}{l}\text { Collection } \\
\text { site }\end{array}$ & $\begin{array}{c}\text { Collection date } \\
(D D / M M / Y Y)\end{array}$ & $\begin{array}{l}\text { Life } \\
\text { stage }\end{array}$ & $\begin{array}{c}\text { T. cruzi } \\
\text { infection }\end{array}$ \\
\hline \multicolumn{12}{|c|}{ Chaquizhca, Loja. } \\
\hline CQ4 & 37.2 & 1.82 & 1.59 & -4.231105 & -79.594118 & CQ306 & Intra-domicile & Kitchen wall & Fcol.09JUL2010 & $\mathrm{F}$ & Positive \\
\hline CQ10 & 66.4 & 1.95 & 1.63 & -4.231105 & -79.594118 & CQ306 & Intra-domicile & Kitchen wall & Fcol.09JUL2010 & $\mathrm{M}$ & n.a \\
\hline CQ11 & 43.8 & 1.85 & 1.57 & -4.231105 & -79.594118 & CQ306 & Intra-domicile & Kitchen wall & Fcol.09JUL2011 & $\mathrm{F}$ & Negative \\
\hline CQ12 & 32.9 & 1.86 & 1.39 & -4.234881 & -79.578047 & CQ406 & Peri-domicile & Chicken nest & Fcol.09JUL2012 & $\mathrm{M}$ & Negative \\
\hline CQ13 & 114.9 & 1.88 & 1.6 & -4.12424 & -79.7059 & TC306 & Peri-domicile & Chicken nest & Fcol.09JUL2013 & $\mathrm{M}$ & Positive \\
\hline \multicolumn{12}{|l|}{ Coamine, Loja. } \\
\hline CE7 & 48.1 & 1.86 & 4.1 & -4.117625 & -79.62101394 & CE509 & Intra-domicile & Bed & Fcol.30JUN2010 & M & Negative \\
\hline CE8 & 74.8 & 1.76 & 1.83 & -4.129398 & -79.60071004 & CE305 & Peri-domicile & Chicken nest & Fcol.30JUN2010 & $\mathrm{F}$ & Negative \\
\hline CE9 & 49.1 & 1.82 & 2.55 & -4.116617 & -79.6163567 & CE505 & Peri-domicile & Hen house & Fcol.30JUN2010 & $\mathrm{M}$ & Positive \\
\hline CE10 & 97.3 & 1.88 & 2.18 & -4.116617 & -79.6163567 & CE505 & Peri-domicile & Hen house & Fcol.30JUN2010 & $\mathrm{F}$ & Positive \\
\hline CE11 & 81.4 & 1.83 & 1.75 & -4.116617 & -79.6163567 & CE505 & Peri-domicile & Hen house & Fcol.30JUN2010 & $\mathrm{M}$ & Negative \\
\hline \multicolumn{12}{|c|}{ La Extensa, Loja. } \\
\hline EX3 & 29.5 & 1.73 & 1.47 & -4.043671 & -79.359601 & EX608 & Peri-domicile & Chicken nest & F. col26JUN2006 & $\mathrm{F}$ & n.a \\
\hline EX8 & 28.5 & 1.65 & 1.25 & -4.043671 & -79.359601 & EX608 & Peri-domicile & Bed & F. col26JUN2006 & $\mathrm{F}$ & n.a \\
\hline EX9 & 32.5 & 1.76 & 2.15 & -4.04413 & -79.35964 & EX803 & Peri-domicile & Chicken nest & F. col8AUG2007 & $\mathrm{F}$ & Negative \\
\hline EX10 & 52.7 & 1.74 & 1.4 & -4.04413 & -79.35964 & EX803 & Peri-domicile & Chicken nest & F. col8AUG2007 & $\mathrm{F}$ & Negative \\
\hline EX11 & 150.9 & 1.87 & 1.5 & -4.04413 & -79.35964 & EX803 & Peri-domicile & Chicken nest & F. col8AUG2007 & $\mathrm{F}$ & Negative \\
\hline
\end{tabular}




\section{Bejuco, Manabí.}

\begin{tabular}{|c|c|c|c|c|c|c|c|c|c|c|c|}
\hline BJ5 & 72.7 & 1.81 & 1.64 & -0.9728 & -80.3445 & BJN55-1 & Peri-domicile & Rat nest & F. col23JUN2007 & $\mathrm{M}$ & n.a \\
\hline BJ10 & 25.7 & 1.67 & 1.73 & -0.9728 & -80.3445 & TBJ1940 & Peri-domicile & Chicken nest & Fcol.07JUL2009 & $\mathrm{M}$ & n.a \\
\hline BJ11 & 71.1 & 1.8 & 1.52 & -0.9728 & -80.3445 & TBJ1941 & Peri-domicile & Chicken nest & Fcol.07JUL2009 & $M$ & n.a \\
\hline BJ12 & 40.5 & 1.86 & 1.93 & -0.9728 & -80.3445 & TBJ2009 & Peri-domicile & Chicken nest & Fcol.130CT2009 & $\mathrm{M}$ & n.a \\
\hline BJ13 & 105.4 & 1.8 & 1.48 & -0.9728 & -80.3445 & TBJ2010 & Peri-domicile & Chicken nest & Fcol.130CT2009 & M & n.a \\
\hline
\end{tabular}

